\title{
MEMBANGUN MENTAL POSITIF PARA PEKERJA DAN PENYULUHAN HAK-HAK PEKERJA YANG DI PHK ATAU YANG MENDAPATKAN DAMPAK COVID 19
}

\author{
Khairunnisa, Iin Indriani, Nurhayati, Achmad Hanafi Setiawan, Tahta Anedea \\ Universitas Pamulang \\ Email: dosen00743@unpam.ac.id
}

\begin{abstract}
The existence of an epidemic (Covid 19), directly affected workers, namely the Termination of Employment (FLE). The need for counseling is given to workers in the Workers 'Union in the Tangerang area as well as workers outside of the Workers' union affected by Covid 19. Methods used by methods of counseling and discussion. Counseling given about the rights received by workers affected by layoffs and impacts covid 19, based on legal aspects and building a positive mentality for workers affected by the epidemic. The activity is expected to increase the knowledge and visiont of workers regarding the law on the rights received, so that workers understand what they need to be accepted and are able to understand the problem in the right ways, In addition, the workers can positively the problem with mental establishment in order to take strategic steps toward creating new jobs.
\end{abstract}

Keywords: Layoffs, positive mentality, rights, workers

\begin{abstract}
Abstrak
Adanya wabah (Covid 19), secara langsung berdampak pada pekerja yaitu adanya Pemutusan Hubungan Kerja (PHK). Perlunya penyuluhan diberikan kepada para pekerja yang ada dalam Serikat Pekerja di daerah Tangerang maupun pekerja di luar dari serikat Pekerja yang terkena dampak Covid 19. Metode yang digunakan dengan metode penyuluhan dan diskusi. Penyuluhan yang diberikan mengenai hak -hak yang diterima para pekerja terkena PHK maupun dampak covid 19, berdasarkan aspek hukum serta membangun mental positif bagi para pekerja terkena dampak pandemik. Kegiatan diharapkan dapat meningkatkan pengetahuan dan wawasan para pekerja mengenai hukum tentang hak -hak yang diterima, sehingga para pekerja memahami apa saja yang harus diterima dan mampu menyampaikan problemnya dengan cara -cara yang benar, selain itu para pekerja bisa memahami permasalahan secara positif dengan mental yang dibangun agar dapat mengambil langkah yang strategis dalam menciptakan pekerjaan baru. Dari 15 peserta yang hadir sebagian besar responnya positif.
\end{abstract}

Kata kunci: PHK, Mental positif, Hak, Pekerja. 


\section{A. PENDAHULUAN}

Menyikapi kondisi wabah Covid-19, dan dalam upaya mendukung Gugus Tugas Percepatan Penanganan Covid-19, Kadin Indonesia sebagai wadah organisasi bagi pelaku usaha di Indonesia dimana dalam kegiatan utama organisasi ini adalah membantu perekonomian bangsa demi mewujudkan kehidupan ekonomi dan dunia usaha yang berdasarkan Pasal 33 UUD 1945, maka Kadin Indonesia mengeluarkan panduan (guidance) perencanaan berkesinambungan bisnis untuk perusahaan dan terutama untuk perusahaan kecil dan menengah di Indonesia. PHK kepada pekerja/buruh oleh perusahaan sering kali menimbulkan adanya kesenjangan sosial oleh karena tidak cakapnya suatu perusahaan untuk memenuhi kriteria-kriteria PHK yang dijatuhkan kepada karyawannya.

Adapun perumusan masalah Mitra, sebagai berikut :

1. Mengapa diperlukan penanaman mental positif bagi pekerja?

2. Bagaimanakah hak-hak pekerja yang megalami pemutusan hubungan kerja sebagai dampak dari pandemik covid-19?

Solusi yang ditawarkan kepada Serikat Pekerja, sebagai berikut :

1. Penyuluhan dan diskusi dengan pola manajemen konflik sebagai upaya membangun mental yang positif.

2. Penyuluhan mengenai Undang-Undang ketenagakerjaan dengan serikat Pekerja dan para pekerja yang mengalami PHK maupun yang terkena dampak covid 19.

\section{B. METODE PELAKSANAAN KEGIATAN}

Metode yang digunakan dalam PKM ini ada 2 (dua), yaitu

1. Metode ceramah dengan cara persentasi / atau penyuluhan

2. Tanya jawab (diskusi).

Adapun pemaparan materi dilakukan dengan cara presentasi, pada kegiatan PKM ini terdapat 2 materi, yaitu :

1. Materi pertama adalah penyuluhan hak-hak pekerja korban pemutusan hubungan kerja sebagai dampak pandemik Covid-19 dengan narasumber Nurhayati, S.H, M.H yang berisi penjelasan Undang-Undang Ketenagakerjaan terkait data dan informasi yang di dapatkan dari lapangan mengenai implementasi Undang-Undang Ketenagakerjaan. Termasuk menjelaskan tentang hak - hak sebagai pekerja yang di PHK dalam situasi yang terkena dampak Covid 19 sesuai dengan aturan hukum yang berlaku. Penjelasan ini disampaikan selama 30 menit dan dilanjutkan dengan sesi tanya jawab. Sesi tanya jawab dibagi menjadi 2 sesi yaitu masing-masing sesi terdapat 3 pertanyaan. Sesi tanya jawab ini bertujuan agar peserta lebih aktif dan mengali lebih dalam materi berkaitan dengan Undang-Undang Ketenagakerjaan.

2. Materi kedua adalah membangun mental Positif dengan narasumber Khairunnisa, S.Psi, M.Si yang berisi bagaimana membangun mental yang baik dan karakter apa saja yang harus ditanamkan untuk membangun mental dalam menghadapi dampak covid 19 yaitu terdiri dari berinisiatif, berkeahlian, optimis, percaya diri, jujur dan berani mengambil resiko, mempunyai daya imajinasi, tanggung jawab, dan kontrol semua 
tindakan yang dipilih. Selain karakter diatas, mental Positif juga dapat dilihat dari karakter Rasulullah SAW dengan empat karakteristik, yaitu; Fatonah. Menekankan pada proses berpikir positif, kreatif kritis dan analitis terkait menghadapi dampak dari PHK. Pemaparan materi dilakukan dilakukan 30 menit dan dilanjutkan dengan sesi tanya jawab. apa saja yang perlu dilakukan agar tetap dalam kondisi stabil pada masa Pademi.

\section{HASIL DAN PEMBAHASAN}

Hasil dari kegiatan ini adalah tebentuknya motivasi dari para pekerja yang terdampak, memahami tips-tips mengenai pengembangan kebiasaan baru yang positif, mengembangkan relasi baru dan meningkatnya kesadaran hukum (M. Iqbal, 2019:2) para serikat pekerja yang terkena Pemutusan Hubungan Kerja (PHK) dampak dari wabah Covid 19 tentang sedikitnya berdasarkan 3 (tiga) dasar hukum. Pemerintah dengan pihak Pekerja dan Pengusaha melakukan perundingan (win win solution) menentukan Pasal 93 (3) Undang-Undang 13 Tahun 2003 sebagai acuan, untuk mempertemukan Pengusaha dan Pekerja menyepakati pembayaran upah buruh. sebesar 100\% untuk 4 bulan pertama, $75 \%$ untuk 4 bulan kedua, dan 50\% untuk ketiga, dan sesudah itu Pengusaha dapat mem PHK pekerjanya atau melanjutkan hubungan kerja dengan pekerjanya. Pandemi COVID-19 yang mengakibatkan Perusahaan benar- benar tutup berhenti/tidak jalan lagi, atau karena keadaan memaksa (force majeure) (Iin Indriani, 2017: 254), menurut Pasal 164 ayat (1) Undang-Undang 13/2003, Pengusaha dapat mem-PHK pekerjanya, dengan kewajiban membayar pesangon 1 x Pasal $156(2,3,4)$. Pandemi COVID 19 yang mengakibatkan Perusahaan Tutup karena tidak mengalami kerugian, dan tidak mengalami "Force Majeure" (Sunija, 2020:25), melainkan melakukan "Efisensi", maka Perusahaan wajib membayar 2 x Pasal 156 (2), dan 1 x Pasal 156 (3), (4). Dampak lain dari kemampuan untuk menyesuaikan diri dengan diri sendiri, orang lain dan masyarakat serta lingkungan di mana ia hidup maka masyarakat dapat berpikir positif dan mengembangkan kemampuan dalam dirinya untuk lebih produktif (Ma'rifattullah, 2016:17). Serta kesadaran hukum, ini juga dapat berpengaruh bagi peningkatan pola pikir serikat pekerja yakni dengan meningkatkan kreativitas yang menghasilkan (Iin Indriani, 2019:597).

\section{Tahap Persiapan}

Sebelum melaksanakan Pengabdian Kepada Masyarakat kami selaku Dosen Universitas Pamulang melakukan pra-survey kepada beberapa perkumpulan serikat pekerja di wilayah Tangerang selatan. Berdasarkan data dan informasi yang kami dapatkan bahwa ada banyak yang terkena PHK sebagai dampak covid-19.

Hal ini menuntut para pekerja untuk memahami ketentuan hukum terkait hak dan kewajiban pekerja di Perusahaan, agar menghindari segala hal yang merugikan pekerja.

Setelah itu, TIM PKM yang terdiri dari lima orang Dosen UNPAM melakukan Forum Group Discussion (FGD) untuk mempersiapkan pelaksanaan Pengabdian Kepada Masyarakat (PKM) di Serikat Pekerja DPC Tangerang. 
2. Tahap Pelaksanaan Pengabdian Kepada Masyarakat

Pelaksanaan Pengabdian Kepada Masyarakat dilakukan dalam Forum Group Diskusi pada tanggal 20 Mei 2020. Kegiatan dilaksanakan online kepada seluruh peserta dalam perkumpulan serikat pekerja wilayah Tangerang dan sekitarnya dengan tema "Membangun Mental Positif Para Pekerja Dan Penyuluhan Hak- Hak Pekerja Yang Di PHK Atau Yang Mendapatkan Dampak COVID 19”. Kegiatan ini di ketuai oleh Ibu Khairunnisa, S.Psi, M.Psi dengan narasumber Bapak Fathur Rahman, SH., MH dibantu dosen UNPAM lainnya yaitu dan Ibu Khairunnisa, S.Psi., M.Psi,Nurhayati, SH., MH. Kegiatan PKM ini dihadiri pekerja yang bergabung dalam serikat pekerja DPC wilayah Tangerang dan sekitarnya.

\section{Tahap Pelatihan}

Untuk melaksanakan kegiatan tersebut digunakan beberapa metode pelatihan yaitu: Metode Ceramah

a. Metode ceramah dipilih untuk memberikan penjelasan tentang pentingnya mengetahui tips membangun mental positif dan cara penuntutan hak- hak pekerja yang terkena PHK dengan jalur hukum yang benar.

b. Metode Tanya Jawab

Metode Tanya jawab sangat penting bagi para peserta pelatihan. Metode ini memungkinkan para peserta menggali pengetahuan sebanyak-banyaknya tentang pengelolaan mental positif dan hak -hak pekerja yang terkena PHK.

Metode Simulasi

Metode simulasi ini diberikan kepada para peserta penyuluhan dengan memberikan contoh inovasi dan tips sebagai upaya peningkatan pengembangan mental positif dan penuntutan hak-hak benar

\section{KESIMPULAN DAN SARAN}

\section{Simpulan}

Berdasarkan Hasil dan Pembahasan dapat disimpulkan sebagai berikut :

1. Diperlukan penanaman mental positif bagi pekerja dalam kondisi pademi saat ini, agar para pekerja dapat menghadapinya dengan strategi yang bisa membangkitkan kondisi ekonominya. Sebab hanya dengan mental positiflah seseorang dapat mencari alternatif solusi yang menguntungkan bagi diri, keluarga dan lingkungannya.

2. Hak-hak pekerja yang mengalami pemutusan hubungan kerja sebagai dampak Covid 19 salah satuya bisa menggunakan hubungan indusrial dalam mengatasinya dengan merujuk pada Pasal 150 sampai dengan Pasal 172 Undang-Undang No. 13 Tahun 2003 Tentang Ketenagakerjaan.

\section{Saran}

Berdasarkan hasil kesimpulan yang didapatkan dalam Pengabdian Kepada Masyarakat yaitu

1. Disarankan kepada pekerja untuk selalu berpikir positif agar tidak mudah stress.

2. Diharapkan kedepannya dosen Universitas Pamulang dapat meningkatkan pembinaan lanjutan terkait hal-hal yang diperlukan pekerja atau masyarakat dengan waktu yang berkelanjutan dan metode pengabdian yang berbeda dari yang telah dilakukan yaitu Penyuluhan. 
Ucapan Terima Kasih

Rasa syukur dan suka cita kami haturkan kepada segenap pihak yang telah mensukseskan kegiatan PKM dengan judul "Membangun Mental Positif Para Pekerja Dan Penyuluhan Hak-Hak Pekerja Yang Di Phk Atau Yang Mendapatkan Dampak Covid 19" kepada:

1. Rektor Dr. H. Dayat Hidayat, M.M, Rektor Universitas Pamulang Tangerang Selatan Banten.

2. Dr. Ali Maddinsyah, S.E., M.M., selaku Ketua LPPM Universitas Pamulang Tangerang Selatan - Banten.

3. Fathur Rahman selaku Koordinator Serikat Pekerja.

4. Mahasiswa Universitas Pamulang yang juga ikut berkontribusi terhadap kelancaran kegiatan PKM.

5. Dosen Pengabdi Program Studi Teknik Industri Fakultas Teknik Universitas Pamulang

\section{DAFTAR PUSTAKA}

Indriani, I. (2017, December). Perkembangan Hukum: Perseroan Terbatas Dan Praktik Penggunaan Nominee Oleh Investor Asing. In PROCEEDINGS (Vol. 2, No. 1).

Indriani, I. (2019). Pengaruh Perkembangan Pembangunan Nasional Sebagai Aspek Pengubah Hukum Dari Segi Ekonomi. Rechtsregel Jurnal Ilmu Hukum, 2(1).

Iqbal, M. (2019). Efektifitas Hukum Dan Upaya Menangkal Hoax Sebagai Konsekuesni Negatif Perkembangan Interkasi Manusia. Literasi Hukum, 3(2), 1-9.

Ma'rifattullah, I. (2016). Hubungan Antara Kecerdasan Emosi dan Kepercayaan Diri Karyawan Terhadap Kecemasan Isu Pemutusan Hubungan Kerja (PHK) Pada Karyawan. Psikoborneo, 4(3).

Sunija, D. A., Febriani, S., Raharjo, S. T., \& Humaedi, S. (2020). Pekerja Sosial Industri Dalam Menangani Permasalahan Phk Di Dunia Industri Indonesia. Prosiding Penelitian Dan Pengabdian Kepada Masyarakat, 6(3), 181-191.

Undang-Undang Republik Indonesia No. 13 Tahun 2003 Tentang Ketenagakerjaan 